Acta Theriologica 39 (4): 417-424, 1994.

PL ISSN 0001-7051

\title{
Faeces count as an index of fox abundance
}

\author{
Paolo CAVALLINI*
}

\begin{abstract}
Cavallini P. 1994. Faeces count as an index of fox abundance. Acta theriol. 39: 417-424.
Faeces were collected monthly along transects in 9 areas of the Pisa province, central Italy, from April 1992 to March 1993 (total $\mathrm{km}$ walked = 982). An index of fox abundance ( $n$ of faeces per $\mathrm{km}$ ) was computed. It was negatively influenced by rainfall in the 20 days preceding the transect, but was unrelated to the percentage of plant material in the diet. Differences among areas (averages from 0.338 to 2.966 faeces per $\mathrm{km}$ ) were significant $(p<0.0001)$ and consistent throughout the year. Faeces were randomly distributed along the transects. The index may therefore provide an efficient and inexpensive method to evaluate relative abundance of foxes, but comparisons should include only areas and periods with similar rainfall. Seasonal population fluctuations are not detectable. Best results may be obtained when rainfall in the 20 days preceding the transect did not exceed $50 \mathrm{~mm}$.

University of Siena, Department of Evolutionary Biology, via Mattioli 4, 53100 Siena, Italy, and University of Pisa, Department of Environmental and Territorial Sciences, via Volta 4, 56100 Pisa, Italy

Key words: Red fox Vulpes vulpes, abundance index, Italy
\end{abstract}

\section{Introduction}

Red foxes Vulpes vulpes Linnaeus, 1758 are difficult (and, in many environments, impossible) to census accurately (Kolb 1982, Phillips 1982). A variety of methods have been used: counts of reproductive dens (Insley 1977, Page 1981, Harris and Rayner 1986a, b, Hewson 1986, Coman et al. 1991, Meia and Weber 1992, Allen and Sargeant 1993), hunting or questionnaire statistics (Lloyd 1968, Kolb and Hewson 1980, Harris 1981, Hatcher and Shaw 1981, Hewson 1984, Lindström 1991), scent stations (Hatcher and Shaw 1981, Rau et al. 1985), spotlighting (Stahl 1990, Stahl and Migot 1990, Weber et al. 1991, Marlow 1992), track counts on snow (Pulliainen 1981, Goszczyński 1989) and on sand (Rau et al. 1985, Servin et al. 1987), or faeces counts along transects (Kolb and Hewson 1980, Rau et al. 1985). Of these methods, only exhaustive den counts allow the estimation of absolute density, when applied in limited areas that can be easily searched (i.e. with little cover). Den counts, however, require an extensive knowledge of the area, and are expensive and time-consuming (especially for medium to large areas). The other methods index relative density only, and all suffer from various

* Mailing address: via Mazzini 64, 56025 Pontedera (PI), Italy 
limitations: hunting and questionnaire statistics are dependent on sociological variables, are influenced by human attitudes toward the fox, and therefore comparisons among areas are difficult; response to scent stations may be influenced by previous fox experience (Andelt et al. 1985), and therefore is dependent on hunting (especially trapping) intensity in the area. Spotlighting can be used only in areas with little or no cover. Track counts require snow cover or rather infrequent soil conditions. Faeces counts may be influenced by diet (particularly on the percentage of poorly digested items such as fruit; Andelt and Andelt 1984) and rainfall. However, the effect of diet on faeces counts has been quantified only for coyotes Canis latrans, whereas the effect of rainfall has never been investigated. Before faeces deposition rates can be used as a reliable indicator of density and trends in abundance, the effect of other relevant variables should be documented (Andelt and Andelt 1984).

The aim of this paper is to evaluate the consistency of faeces counts as an index of fox density and the influence of fruit consumption and rainfall on it.

\section{Study area and methods}

Studies were carried out in nine areas uniformly distributed within the Pisa province $\left(43^{\circ} \mathrm{N}\right.$, $\left.10-11^{\circ} \mathrm{E}\right)$, central Italy. The region $\left(52 \mathrm{~km} \mathrm{E}-\mathrm{W}\right.$ by $\left.75 \mathrm{~km} \mathrm{~N}-\mathrm{S} ; 2,448 \mathrm{~km}^{2}\right)$ is mostly flat and intensively cultivated (mainly cereals) in the North, becoming increasingly hilly (up to $800 \mathrm{~m}$ a.s.l.) and wooded towards the South. Climate is Mediterranean, with mild winters and dry, hot summers. Snow occurs very rarely. The nine areas are (Fig. 1): two on the coastal plains (Vecchiano and Coltano), one on the Monti Pisani (Mounts of Pisa; up to $980 \mathrm{~m}$ a.s.l.), two on the Arno and Era valleys (Lucagnano and Collebrunacchi), two on the coastal hills (S. Luce and Laiatico-Orciatico), and two on the southern hills (Berignone and Rio-Arbiaia). Foxes were hunted (up to 1 fox per $\mathrm{km}^{2}$; in 1992 more than 330 foxes were killed in the whole province) in all areas except Berignone (a protected reserve) and Monti Pisani (where they are shot only occasionally; Cavallini 1994).

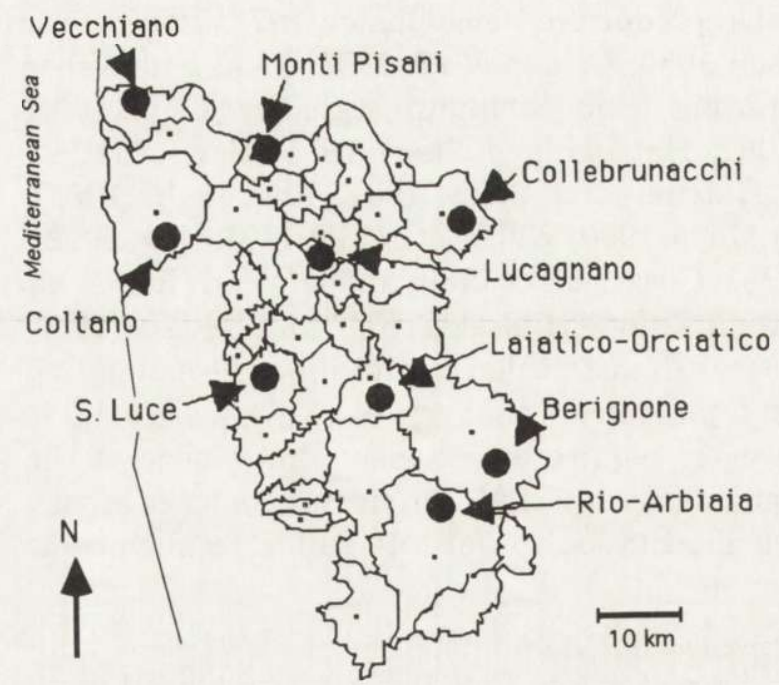

Fig. 1. Localization of sampling areas for the collection of faeces within Pisa province, central Italy. Lines enclose administrative units (communes), and small dots indicate main towns thereof. 


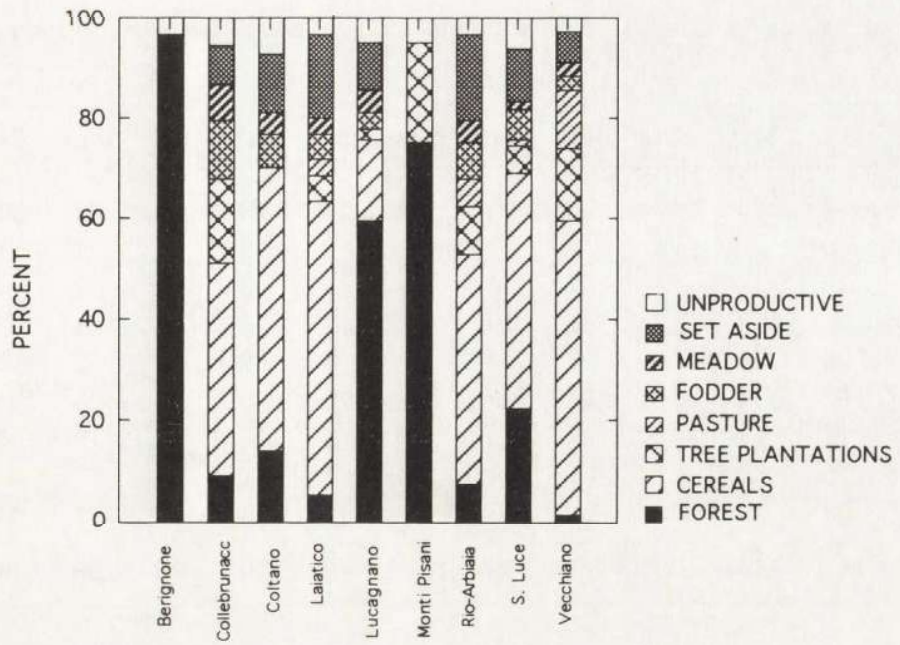

Fig. 2. Habitat composition in the 9 sampling areas.

Most areas (6 of 9) were dominated by grassland (mainly cultivated), whereas Berignone, Monti Pisani and Lucagnano were more wooded (Fig. 2). On each area a transect was established, ranging from 6.2 to $14.4 \mathrm{~km}$ in length. Due to local phenomena (e.g. floods, landslides), small sections of the transects $(\leq 10 \%)$ could not be inspected in some months. To avoid bias from differential visibility of faeces, transects were located along paths of similar width. Each transect was searched for faeces on foot at 1-month intervals. Sampling started in April 1992 until March 1993, for a total of $982 \mathrm{~km}$. Fox faeces were identified on the basis of diameter, shape, and odour (e.g. Bang and Dahlstrom 1974). Location of faecal samples was plotted on a map $(1: 5,000$ or 1:25,000), and distance between each sample and the following one was estimated. Distances $<100 \mathrm{~m}$ were estimated in the field. The coefficient of variation of distances (hereafter CV) was computed as an index of faeces dispersion: a $\mathrm{CV}$ close to 0 indicates regular spacing, a $\mathrm{CV}$ close to 1 indicates random spacing, and a $\mathrm{CV}$ much larger than 1 denotes clumped distribution. To stabilise variance, the CV was computed only for the 47 transects in which $\geq 10$ faeces were collected. An index of faeces frequency was computed as $n$ of faeces per $\mathrm{km}$ of transect. Percentage of fruit in the diet was determined by laboratory analysis (estimated volume of the ingested food; following Kruuk and Parish 1981). Rainfall data (mm of rain fallen in the 20 days preceding the transect) were taken from the meteorological station closest to each transect $(<8 \mathrm{~km}$; Ufficio Idrografico del Genio Civile di Pisa).

\section{Results}

Altogether 1293 faecal samples were collected during the 108 transects; both seasonal and local variability was high (Table 1). The CVs of distances between faeces for each transect ranged from 0.71 to 1.89 , with an average of $1.33 \pm 0.30$ SD. No significant difference among areas was found (Kruskal-Wallis ANOVA, $H$ $=10.14, p=0.18, n=47$ ). Faeces therefore followed an approximately random distribution along transects.

The faeces index was highest (> 1.5 samples per $\mathrm{km}$ ) in spring (March to May) and in summer (July and August), and lowest ( $<1$ sample per $\mathrm{km}$ ) in autumn 
Table 1. Number of fox faeces collected in each month in the 9 sampling areas in Pisa province, central Italy.

\begin{tabular}{lrrrrrrrrrrrrr}
\hline & Apr & May & June & July & Aug & Sep & Oct & Nov & Dec & Jan & Feb & Mar & Total \\
\hline Berignone & 37 & 22 & 10 & 11 & 25 & 71 & 12 & 23 & 17 & 42 & 22 & 66 & 358 \\
Collebrunacchi & 0 & 2 & 4 & 4 & 1 & 4 & 3 & 2 & 1 & 1 & 2 & 5 & 29 \\
Coltano & 10 & 11 & 3 & 3 & 4 & 16 & 0 & 3 & 3 & 7 & 6 & 8 & 74 \\
Laiatico-Orciatico & 3 & 3 & 3 & 2 & 10 & 11 & 7 & 3 & 1 & 1 & 3 & 3 & 50 \\
Lucagnano & 6 & 14 & 6 & 6 & 9 & 8 & 0 & 2 & 4 & 3 & 3 & 2 & 63 \\
Monti Pisani & 62 & 34 & 22 & 19 & 29 & 15 & 10 & 5 & 5 & 25 & 16 & 22 & 264 \\
Rio-Arbiaia & 12 & 14 & 8 & 5 & 15 & 17 & 5 & 16 & 2 & 3 & 5 & 4 & 106 \\
S. Luce & 28 & 39 & 27 & 16 & 4 & 11 & 1 & 11 & 1 & 7 & 16 & 11 & 172 \\
Vecchiano & 22 & 19 & 26 & 14 & 25 & 6 & 11 & 5 & 1 & 7 & 17 & 24 & 177 \\
Total & 180 & 158 & 109 & 80 & 122 & 159 & 49 & 70 & 35 & 96 & 90 & 145 & 1293 \\
\hline
\end{tabular}

(October to December). The trend was consistent among areas (Fig. 3a). Monthly standard errors of the index were higher (i.e. difference among areas was higher) during spring and summer, when averages were also higher, and lowest in winter, when index was low. Yearly averages range from over 2 faeces per $\mathrm{km}$ (Monti Pisani and Berignone) to less than 1 (S. Luce, Lucagnano, Laiatico, Coltano, Collebrunacchi). Two areas (Vecchiano and Rio-Arbiaia) had intermediate values (Table 2). The differences were consistent throughout the year (ANCOVA, with month as a covariate: $F=10.22, p<0.0001, n=108$ ). The two areas with the highest indices were more wooded and hunting-free and the area with the lowest index has been severely hunted during the 1992 spring ( $>0.5$ foxes per $\mathrm{km}^{2}$; Cavallini 1994), but one of the areas with intermediate frequency (Vecchiano) had relatively high hunting pressure (>0.22 foxes per $\mathrm{km}^{2}$; Cavallini 1994). Rainfall during the 20 days before the transect inspection had a significant influence on
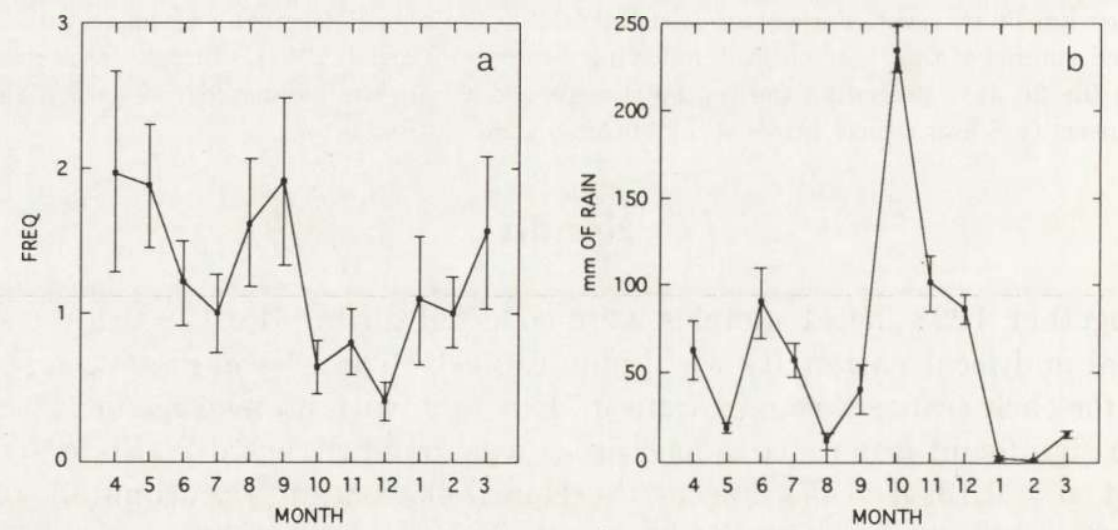

Fig. 3. (a) Average index of fox abundance ( $n$ of faeces per $\mathrm{km}$ ) for the 9 sampling areas from April 1992 through March 1993. (b) Average cumulative rainfall ( $\mathrm{mm}$ of rain) in the 20 days preceding each transect among the 9 sampling areas. Vertical lines indicate the standard errors of the mean. 
Table 2. Length of transects and index of fox abundance ( $n$ of faeces per km; yearly average of monthly frequencies and SD are given) for the 9 sampling areas in Pisa province, central Italy. Averages labelled with the same letter are not statistically different (Tukey multiple comparisons test, $p<0.001$ ).

\begin{tabular}{lrrlll}
\hline \multirow{2}{*}{ Area } & \multicolumn{2}{c}{ Lenght of transects $(\mathrm{km})$} & & \multicolumn{2}{c}{ Abundance index } \\
\cline { 2 - 3 } \cline { 5 - 6 } & mean & $\mathrm{SD}$ & & mean & SD \\
\hline Berignone & 13.57 & 1.27 & & $2.24 \mathrm{AB}$ & 1.66 \\
Collebrunacchi & 6.80 & 0.67 & & $0.34 \mathrm{C}$ & 0.21 \\
Coltano & 10.25 & 0.82 & & $0.60 \mathrm{C}$ & 0.45 \\
Laiatico-Orciatico & 6.70 & 0.24 & & $0.62 \mathrm{C}$ & 0.49 \\
Lucagnano & 6.20 & 0.00 & & $0.85 \mathrm{C}$ & 0.62 \\
Monti Pisani & 7.18 & 0.50 & & $2.97 \mathrm{AB}$ & 1.74 \\
Rio-Arbiaia & 7.03 & 0.57 & & $1.37 \mathrm{BC}$ & 1.02 \\
S. Luce & 14.37 & 1.38 & & $0.91 \mathrm{C}$ & 0.65 \\
Vecchiano & 9.77 & 0.77 & & $1.50 \mathrm{BC}$ & 0.88 \\
\hline
\end{tabular}

faeces frequency (ANOVA, $F=11.91, p<0.001, n=108$ ). Rainfall showed significant variation among months $(F=44.29, p<0.0001, n=108$; Fig. 3b), but not among areas $(F=0.458, p=0.88, n=108)$. The percentage of plant matter in the diet ranged from 0 to $100 \%$ in the various months. Averages for individual areas ranged from $20.5 \pm 20.5 \%$ (Coltano) to $56.1 \pm 15.0 \%$ (Monti Pisani). The overall average was $34.8 \pm 27.45 \%$, most of which (90\%) was represented by fruit. No faecal dropping was found in 4 occasions, thus reducing sample size to 104 . The index of abundance is weakly correlated with plant proportion in the diet $\left(r^{2}=0.671, p=0.048, n=108\right)$. This may indicate either: (1) that a higher availability of fruit supports higher fox densities, (2) that foxes are forced to use also less proteinic resources when living at higher densities, or (3) an index bias: plant consumption may induce the deposition of a higher number of faeces, therefore masking the effect of density on the index (cf Andelt and Andelt 1984). To test for the last possibility, I computed an ANCOVA on the difference of the index among areas, with percentage of plants in the diet as a covariate. The effect of plant consumption is not significant $(F=0.308, p=0.580, n=104)$, when the effect of area $(F=7.791, p<0.0001, n=104)$ is excluded. The index is therefore independent from this source of variation.

\section{Discussion}

The faeces count index gives consistent results throughout the year; the technique is inexpensive, and it can be used as a routine method even by relatively inexperienced observers (i.e. game wardens, students). It can be used also in heavily wooded areas, where spotlighting and den counts are not suitable, and does not require special soil conditions (presence of snow cover or sand). Although 
the true density of foxes in the 9 areas was unknown, the results from faeces counts are coherent with the observed mortality (as estimated by patterns of hunting pressure): foxes appeared more abundant where not hunted, and least abundant where most heavily hunted. The faeces index may therefore be used more widely (e.g. instead of or along with hunting statistics) to estimate relative abundance of foxes.

The distribution of faeces along transects was approximately random, rather than clumped (as postulated by Beltrán et al. 1991). In contrast to other carnivores, foxes do not leave their faeces in middens (Macdonald 1980), and defecate at similar rates in the border and inner parts of home ranges (Goszczyński 1990). This reduces the sample size (and hence transect length) required for a stable estimation of the index (Beltrán et al. 1991). The index is not related to the seasonal fluctuations in fox numbers: it neither increases following spring reproduction (around the end of April; Cavallini 1994) nor decrease during the main fox hunting season (January to April). Rainfall had a strong influence on the index. This might be due to: (1) changes in the behaviour: foxes show seasonal variation in habitat selection in Mediterranean habitats (Cavallini and Lovari 1991, 1994). However, the fluctuations of the index are consistent across areas, despite large habitat differences among them. Moreover, transects always crossed all major habitats in each area; (2) changes in the detectability of faeces; during summer, the grass is much taller and thicker, which could make detection of samples more difficult. The index, however, is at his lowest in winter, when the grass is short; (3) changes in the speed of disintegration of faeces. This is the most likely explanation of the observed trend: casual observations of known-age faeces ( $n=$ 19) showed that faeces persist in the field, with very little sign of degradation, until the first rainfall; heavy rains wash faeces away, whereas lighter rains tend to break them (P. Cavallini, pers. obs.).

Because of the influence of rainfall, I suggest that the index should be used preferentially when under $50 \mathrm{~mm}$ of rain have fallen in the 20 days preceding the transect. In this case, the effect seems slight, and differences among areas are larger (i.e. the index is more sensitive; see Fig. 3a). Rainfall effect is also a strong limitation when comparing fox abundance in different seasons (as attempted by Kolb and Hewson 1980). Without knowledge of rainfall pattern, seasonal variations in the index may be erroneously interpreted as related to fox biological cycle (e.g. recruitment of young). In this case, the index cannot be recommended. On the other hand, the influence of the diet on the abundance index is irrelevant, at least in my study area. This variable may therefore be overlooked in future surveys, except perhaps in areas where fruit consumption is higher and/or more variable among areas (e.g. Ciampalini and Lovari 1985, Cavallini and Lovari 1991, Lovari et al. 1994). Without the need for diet analysis, routine surveys will require far less time and skill.

The estimate of absolute numbers (attempted by Rau et al. 1985) may be confused by at least two factors: (1) non-random distribution of faeces by foxes 
(influenced by social and trophic factors; Macdonald 1980); while the distribution along the tracks may be near-random (as shown by this study), the preference of foxes for tracks may make the overall distribution skewed; (2) differential defecation rates (influenced by food habits, digestibility of various food items, and physiological variations among and between individuals; Ryszkowski et al. 1971). All these factors require an extensive knowledge of the fox population(s) under study which is not generally available (see also Kolb 1982).

The faeces index may be an efficient method also for surveys on other species, provided that (1) they live in dry areas, or transects are conducted during the dry season; (2) they tend to defecate along paths and roads (Macdonald 1980); (3) their faeces are easily distinguished from those of other sympatric carnivores.

Acknowledgements: Funding for this study has been provided by the Amministrazione Provinciale di Pisa (M. Franceschini). T. Volpi and S. Santini greatly helped during field work and laboratory analysis. The guidance and support of Prof R. Nobili, Prof S. Lovari and Prof R. Dallai made this study possible. The Museum of Natural History of the University of Pisa and the Museum of Natural History of Livorno provided logistic support.

\section{References}

Allen S. H. and Sargeant A. B. 1993. Dispersal patterns of red foxes relative to population density. J. Wildl. Manage. 57: 526-533.

Andelt W. F. and Andelt S. H. 1984. Diet bias in scat deposition-rate surveys of coyote density. Wildl. Soc. Bull. 12: 74-77.

Andelt W. F., Harris C. E. and Knowlton F. F. 1985. Prior trap experience might bias coyote responses to scent stations. SWest. Nat. 30: 317-318.

Bang P. and Dahlstrom P. 1974. Animal tracks and signs. Collins, London: 1-235.

Beltrán J. F., Delibes M. and Rau J. R. 1991. Methods of censusing red fox (Vulpes vulpes) populations. Hystrix 3: 199-214.

Cavallini P. 1994. Variations in the biology of the red fox Vulpes vulpes (Linnaeus). Ph. D. thesis, University of Siena: $1-120$.

Cavallini P. and Lovari S. 1991. Environmental factors influencing the use of habitat in the red fox, Vulpes vulpes (L., 1758). J. Zool., Lond. 223: 323-339.

Cavallini P. and Lovari S. 1994. Home range, habitat selection and activity of the red fox in a Mediterranean coastal ecotone. Acta theriol. 39: 279-287.

Ciampalini B. and Lovari S. 1985. Food habits and trophic niche overlap of the badger (Meles meles L.) and the red fox (Vulpes vulpes L.) in a Mediterranean coastal area. Z. Säugetierk. 50: 226-234.

Coman B. J., Robinson J. and Beaumont C. 1991. Home range, dispersal and density of red foxes (Vulpes vulpes L.) in Central Victoria. Wildl. Res. 18: 215-223.

Goszczyński J. 1989. Population dynamics of the red fox in central Poland. Acta theriol. 34: 141-154.

Goszczyński J. 1990. Scent marking by red foxes in Central Poland during the winter season. Acta theriol. 35: 7-16.

Harris S. 1981. An estimation of the number of foxes (Vulpes vulpes) in the city of Bristol, and some possible factors affecting their distribution. J. Appl. Ecol. 18: 455-465.

Harris S. and Rayner J. M. V. 1986a. A discriminant analysis of the current distribution of urban foxes (Vulpes vulpes) in Britain. J. Anim. Ecol. 55: 605-611.

Harris S. and Rayner J. M. V. 1986b. Urban fox (Vulpes vulpes) population estimates and habitat requirements in several British cities. J. Anim. Ecol. 55: 575-591. 
Hatcher R. T. and Shaw J. H. 1981. A comparison of three indices to furbearer populations. Wildl. Soc. Bull. 9: 153-156.

Hewson R. 1984. Changes in the numbers of foxes (Vulpes vulpes) in Scotland. J. Zool., Lond. 204: 561-569.

Hewson R. 1986. Distribution and density of fox breeding dens and the effects of management. J. Appl. Ecol. 23: 531-538.

Insley H. 1977. An estimate of the population density of the red fox (Vulpes vulpes) in the New Forest, Hampshire. J. Zool., Lond. 183: 549-553.

Kolb H. H. 1982. Red fox (Scotland). [In: CRC handbook of census methods for terrestrial vertebrates. D. E. Davis, ed]. CRC Press, Inc., Boca Raton, Florida: 231.

Kolb H. H. and Hewson R. 1980. A study of fox populations in Scotland from 1971 to 1976. J. Appl. Ecol. 17: 7-19.

Kruuk H. and Parish T. 1981. Feeding specialization of the European badger Meles meles in Scotland. J. Anim. Ecol. 50: 773-788.

Lindström E. 1991. Pattern of spread and effects of sarcoptic mange among red fox populations in Sweden. [In: Global trends in wildlife management. Trans. 18th IUGB Congress, 1987. B. Bobek, K. Perzanowski and W. L. Regelin, eds]. Świat Press, Kraków-Warszawa: 591-595.

Lloyd H. G. 1968. The control of foxes (Vulpes vulpes L.). Ann. Appl. Biol. 61: 334-345.

Lovari S., Valier P. and Ricci Lucchi M. 1994. Ranging behaviour and activity of red foxes in relation to environmental variables, in a Mediterranean mixed pinewood. J. Zool., Lond. 232: 323-339.

Macdonald D. W. 1980. Patterns of scent marking with urine and faeces amongst carnivore communities. Symp. zool. Soc. Lond. 45: 107-139.

Marlow N. J. 1992. The ecology of the introduced red fox (Vulpes vulpes) in the arid zone. Ph. D. thesis, University of New South Wales, Australia: 1-171.

Meia J.-S. and Weber J.-M. 1992. Characteristics and distribution of breeding dens of the red fox (Vulpes vulpes) in a mountainous habitat. Z. Säugetierk. 57: 137-143.

Page R. J. C. 1981. Dispersal and population density of the fox (Vulpes vulpes) in an area of London. J. Zool., Lond. 194: 485-491.

Phillips R. L. 1982. Red fox (U.S.). [In: CRC handbook of census methods for terrestrial vertebrates. D. E. Davis, ed]. CRC Press, Inc., Boca Raton, Florida: 229.

Pulliainen E. 1981. A transect survey of small land carnivore and red fox populations on a subarctic fell in Finnish Forest Lapland over 13 winters. Ann. zool. Fenn. 18: 270-278.

Rau J. R., Delibes M., Ruiz J. and Servin J. I. 1985. Estimating the abundance of the red fox (Vulpes vulpes) in SW Spain. Proc. 17th Congress of the International Union of Game Biologists, Brussels: 869-876.

Ryszkowski L., Wagner C. K., Goszczyński J. and Truszkowski J. 1971. Operation of predators in a forest and cultivated fields. Ann. zool. Fenn. 8: 160-168.

Servin J., Rau J. R. and Delibes M. 1987. Use of radio tracking to improve the estimation by track counts of the relative abundance of red fox. Acta theriol. 32: 489-492.

Stahl P. 1990. Suivi de l'abondance d'une population de renards (Vulpes vulpes) par comptages nocturnes: évaluation de la méthode. Gibier Faune Sauvage 7: 293-309.

Stahl P. and Migot P. 1990. Variabilité et sensibilité d'un indice d'abondance obtenu par comptages nocturnes chez le renard (Vulpes vulpes). Gibier Faune Sauvage 7: 311-323.

Weber J.-M., Aubry S., Lachat N., Meia J.-S., Mermod C. and Paratte A. 1991. Fluctuations and behaviour of foxes determined by nightlighting. Preliminary results. Acta theriol. 36: 285-291.

Received 27 June 1994, accepted 14 September 1994. 